
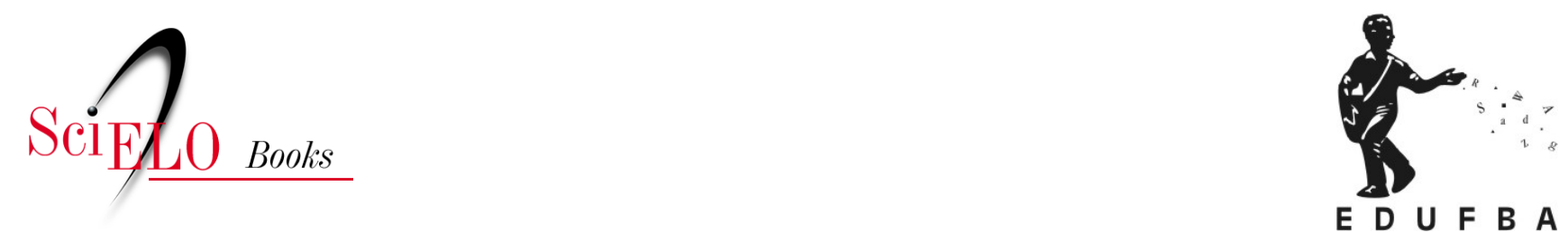

\title{
Por uma microfísica do saber: os contornos da família
}

\author{
Prof. Dr. José Euclimar Xavier de Menezes \\ Fernanda Andrade Leal
}

\section{SciELO Books / SciELO Livros / SciELO Libros}

MENEZES, J.E.X., and LEAL, F.A. Por uma microfísica do saber: os contornos da família. In: MESSEDER, S., CASTRO, M.G., and MOUTINHO, L., orgs. Enlaçando sexualidades: uma tessitura interdisciplinar no reino das sexualidades e das relações de gênero [online]. Salvador: EDUFBA, 2016, pp. 67-80. ISBN: 978-85-232-1866-9. https://doi.org/10.7476/9788523218669.0004.

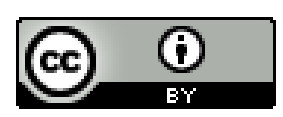

All the contents of this work, except where otherwise noted, is licensed under a Creative Commons Attribution $\underline{4.0 \text { International license. }}$

Todo o conteúdo deste trabalho, exceto quando houver ressalva, é publicado sob a licença Creative Commons Atribição 4.0. 


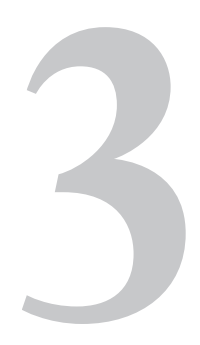

\title{
Por uma microfísica do saber:
} os contornos da família

\author{
ฟNo \\ Prof. Dr. Fosé Euclimar Xavier de Menezes \\ Fernanda Andrade Leal
}

Que estatuto possui o problema da família na obra de Michel Foucault, considerando que, do ponto de vista metodológico, o seu discurso não contempla diretamente este objeto? A comunidade dos estudiosos que se acerca da letra foucaultiana acorda em reconhecê-lo como um autor que privilegia as formas de subjetivação. (VEYNE, I982; GIRAD, I989; TRONCA, I987) Quer dizer, Foucault debate de modo objetivo sobre um tema que perpassa necessariamente os conteúdos sobre a família: o sujeito, a afirmação de sua identidade, a relação que estabelece com os seus pares, os conflitos inerentes a esta 
relação que inflexionam e influenciam as formas de subjetivação. (HAN, I989; FONSECA, 1995)

Desse modo, se a família não é o alvo direto de seu foco e de seu tratamento, o é ao menos transversalmente. Em outros termos, este objeto é capturado pelas teias discursivas do autor quando o seu olhar contempla e atravessa o sujeito e as tramas que inflexionam a sua constituição.

Um outro elemento que desperta o olhar do leitor é o fato de que, a rigor, em todos os textos do autor de História da sexualidade (FOUCAULT, I985) estejam reunidos os discursos derivados de múltiplas ciências do homem, seja no uso singular que Foucault faz de alguns conceitos, seja na critica que o autor dirige aos resultados que tais saberes esboçam nas suas investigações acerca do humano. Para o bem da clareza, tendo sob o seu olhar as figuras do louco, do perverso, do presidiário, do educando, etc., Foucault arrola os saberes que se apropriaram destes objetos, a saber, psicologia, psiquiatria, medicina, psicanálise, direito, pedagogia, etc. Este fato metodológico, precisamente, o recurso de convidar múltiplas disciplinas para o debate em torno de determinados objetos influencia a construção de um olhar acrisolador que recua para detrás do saber que discursa sobre o objeto. Portanto, não se trata de investigar as verdades sobre o objeto, derivadas de aplicações metodológicas determinadas por uma dada ciência, mas sim de inquirir os modos pelos quais tais ciências elaboram as verdades imputadas ao objeto mirado em suas lentes. De todo modo, o procedimento foucaultiano é a um só tempo crítico e multidisciplinar, dadas a extensão, a complexidade, a verticalidade e as perspectivas reunidas pelo autor em suas análises.

Enfim, Foucault constrói um discurso fino que propicia antever a modelagem realizada pelo saber e pelo poder sobre o objeto bomem. Se existe consistência no discurso que se erige sobre o sujeito humano e seu meio, bem como sobre a família na qual ele se insere, tal consistência não advém, com exclusividade, da metodologia aplicada pelos saberes na investigação de seus objetos. A esse delírio onipotente Foucault recusa. $\mathrm{O}$ que suas reflexões encaminham é a construção de um olhar que suspeita não do homem 
ou da família diretamente, mas dos discursos dos saberes que se pretendem construtores das redes conceituais que se apossam desses "objetos”.

Portanto, não faz qualquer sentido indagar acerca do significado que determinada categoria como a familia possui em seu discurso. O que aí é significante é questionar como o seu pensamento acrisolador propõe analisar os resultados que advêm do uso que as ciências humanas realizam em torno deste elemento. Foucault rejeita qualquer que seja o empreendimento epistemológico quando se trata de examinar a elaboração dos saberes e dos seus produtos, convocando-nos para uma tarefa bem mais complexa e, a seu ver, bem mais producente. Ele nos convida a reconstituir uma arqueologia e uma genealogia das ciências humanas. Como elas elaboram as verdades sobre o sujeito e sobre a família? Eis a questão que mais interessa à Foucault.

Esse é o ponto de partida mediante o qual aqui se propõe a leitura pontual da introdução do primeiro volume de História da sexualidade. Qual é a interlocução que Foucault constitui, com quem realiza o seu debate, considerando o cenário sobre o qual o texto se descortina, realizando uma discussão sobre os modos de tratamento da sexualidade na história? Quais dos saberes que se acercam do homem articulam tal discurso? Na abertura do texto, Foucault simula estar de acordo com o diagnóstico das ciências humanas acerca de nossa identidade, pequenos burgueses que somos; simula assentir que a orientação ético-moral burguesa rege a nossa conduta vitoriana; simula consentir que sejamos assujeitados a uma ordem instaurada no século XIX, ordem esta que cataloga, controla, determina como usamos ou não o nosso corpo.

Contudo, não é o que as ciências humanas dizem o que mais interessa ao autor. Não é o conteúdo constitutivo dos enunciados que mais chama a sua atenção. Bem antes, é o modo como esse discurso é construído que interessa. As ciências humanas estabeleceram que, a partir do século XVIII, tenhamos perdido uma tolerância para com as condutas ilícitas relativamente ao sexo, para as quais todos tendemos. Instauramos, com o vitorioso regime, um modo de ser mais comedido, como contraponto 
ao tempo imediatamente anterior, no qual vigorava uma tolerância bem maior aos arroubos de nossa volúpia. Uma normatividade rigorosa, um procedimento mais comedido e controlado para com a nossa sexualidade se tornou o instrumento poderoso de codificação das condutas. É neste ambiente que surge a primeira referência à família:

\begin{abstract}
A sexualidade é, então, cuidadosamente encerrada. Muda-se para dentro de casa. A família conjugal a confisca. E absorve-a, inteiramente, na seriedade da função de reproduzir. Em torno do sexo, se cala. O casal, legítimo e procriador, dita a lei. Impõe-se como modelo, faz reinar a norma, detém a verdade, guarda o direito de falar, reservando-se o principio do segredo. No espaço social, como no coração da moradia, um único lugar de sexualidade reconhecida, mas utilitário e fecundo: o quarto dos pais. (FOUCAULT, i985, p. 9-Io)
\end{abstract}

Vale sopesar o que está sendo dito. O estilo é característico de Foucault: barroco, isto é, as coisas são apresentadas sinuosamente, usando os discursos de um modo flexível na modelagem de uma outra hermenêutica. Foucault não pretende conferir se o que é dito tem sustentação ou não. É quase pacífico aceitar que o regime vitoriano instaurou um molde comportamental negativo, prescritivo, regulamentador, burocrático, funcionalista, determinista em relação à sexualidade. Tal molde prescreve e proíbe. E é exatamente isso que Foucault vai vislumbrar. Como se diz na língua de Foucault, o on dit, sustentado genericamente à moda do disse me disse, instaura, com a Rainha Vitória todo o procedimento burguês relativo à intimidade e investe na direção repressiva. O que fazemos com os nossos corpos parece ser direcionado por um dever, quase que anulando os ditames do desejo. Esse cede lugar aos imperativos enrijecidos daquele.

Não é estranho que seja justamente nesse período que vemos nascer a ciência psicanalítica. $O$ estudo da sexualidade torna-se nessa época, na Europa e nos Estados Unidos, a grande questão do século seguinte e a histeria parecia ser a peça principal. (ROUDINESCO, 20I4, p. 70) O que justifica, aqui, isolarmos o saber psicanalítico dessa cadeia de discursos dos 
saberes sobre os quais se descortinam as indagações e críticas de Foucault. Como a psicanálise elabora as verdades sobre o sujeito e sobre a família? Eis a questão que mais interessa nesse debate. O objetivo é conferir o alcance epistemológico do uso foucaultiano da categoria família.

No seu convite à arqueologia e genealogia das ciências humanas, percebemos o quanto as verdades construídas partem de um modelo de família que vigorava no regime vitoriano. Que as histéricas de Freud tenham ganhado destaque justamente nesse período não nos parece mera coincidência. A histeria parecia antes ser o produto de uma sociedade e de um modelo de família que exercia sobre o sujeito um poder sobre o uso do próprio corpo.

O campo onde essa repressão atuava não podia ser senão a família. É por essa via que a família surge tanto no discurso foucaultiano - como um paradigma, uma referência de conduta para com a sexualidade -, como no discurso psicanalítico - através das histéricas que manifestavam no corpo aquilo que era incompatível com o ideal vitoriano da família burguesa. No primeiro, a família se esgueira como um dispositivo que realiza determinações, a saber: é o espaço e o modelo imperioso do uso do corpo, da realização das legítimas práticas sexuais. A frase mais contundente do autor não deixa margem a interpretação, mas impõe-se como uma evidencia: “[...] o casal, legitimo e procriador, dita a lei”. (FOUCAULT, I985, p. Io)

No segundo, a família é quem adoece o sujeito, pois lhe impõe um modo de conduta que é incompatível com os desejos mais vivos no indivíduo. É o palco do sujeito dividido, culpado de um duplo desejo: matar o pai e possuir a mãe. Mas é, ao mesmo tempo, o lugar de surgimento das subjetividades. Mas se falamos em genealogia e arqueologia das ciências humanas, devemos antes considerar o que se constatava nesse período que figurava como o palco das elaborações freudianas. Quais acontecimentos são relevantes à nossa reflexão?

O principal, e extremamente irrelevante, segundo os autores que debatem a exaustão essa temática (HURSTEL, I999; ROUDINESCO, 2003; ZAFIROPULOS, 200I), o grande acontecimento do século não 
é outro senão o declínio do patriarcado. A família patriarcal que regia seu poder sem contestações perde espaço para o Estado. Essa mudança não acontece sem consequências para a família. $O$ pai fica descreditado socialmente. Essa, ao menos, é a hipótese que Lacan desenvolve em 1938 num

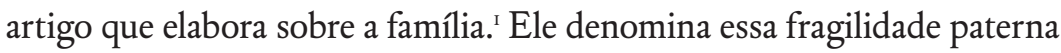
como resultante do "declínio social da imago paterna". Desse declínio surge o que se convenciona como "nascimento de uma nova figura paterna" (ROUDINESCO, 2003, p. 38). A autoridade paterna fica, portanto, submetida a uma outra autoridade, a do Estado. O pai, autoridade moralmente aceita, é antes de tudo submetido, ele também, a uma lei.

Lacan comenta o "declínio social da imago paterna" como uma consequência dos avanços culturais que incidem sobre a família: "Declínio condicionado pelo retorno sobre o indivíduo de efeitos extremos do progresso social, declínio que se manifesta, sobretudo nos nossos dias nas coletividades mais atingidas por esses efeitos: concentração econômica, catástrofes políticas"; mas também como o responsável por "um grande número de efeitos psicológicos", onde, a experiência psicanalítica "levanos a designar aí [na neurose] a determinação principal na personalidade do pai, sempre faltando de certo modo ausente, humilhada, dividida ou artificial” (LACAN, I987, p. 62). O mesmo autor continua

Seja qual for o futuro, este declínio constitui uma crise psicológica. Talvez seja a esta crise que se torna necessário relacionar a aparição da própria psicanálise. $\mathrm{O}$ sublime acaso do génio não explica talvez sozinho que isto aconteça em Viena - nessa altura centro de um Estado que era o melting pot das formas familiares mais diversas, das mais arcaicas às mais evoluídas, dos últimos agrupamentos agnáticos dos camponeses eslavos às formas mais reduzidas do lar pequeno-burguês e às formas mais decadentes da instabilidade da vida comum, passando pelos paternalismos feudais e mercantis - que um filho do patriarcado judeu tenha imaginado o complexo de Édipo. Seja como

${ }^{1}$ Este texto foi publicado, posteriormente, nos Outros Escritos sob o título Complexos familiares na formação do indivíduo. 
for, são as formas de nevroses dominantes no fim do século passado que revelaram ser intimamente dependentes das condições da família.

Mas porque o declínio do pai é tão relevante para Lacan? É na resposta a essa pergunta que encontramos a relação existente entre o declínio do pai e o surgimento da psicanálise. Por um lado, Lacan (1987, p. 62), acreditava que "um grande número de efeitos psicológicos" que correspondiam às neuroses contemporâneas, resultava da imagem desvalorizada do pai que surgia como consequência do que se convenciona como declínio do patriarcado. (ROUDINESCO, 2003) Por outro lado, Lacan observava que o complexo de Édipo surgia como resposta às novas neuroses, as ditas neuroses contemporâneas. Ele chega a afirmar que o complexo de Édipo freudiano "é o nó da maior parte das neuroses" (1987, p. 62) e "define mais particularmente as relações psíquicas na família humana...” (LACAN, I987, p. 45). O que Lacan propunha com essas afirmações? Lacan destacava nada menos do que a existência de uma relação entre o surgimento do complexo de Édipo e as novas formas familiares da modernidade, que por sua vez, se encontravam fundadas na nova figura paterna - a figura de um pai fragilizado socialmente.

Como bem observou Roudinesco (2003, p. 6o) quanto ao uso que Freud faz do Édipo, de Hamlet e dos deuses gregos, este:

[...] delineava com gênio sua grande cena do desejo do incesto e do assassinato do pai. Esta não tinha grande coisa a ver com a peça de Sófocles, nem com os deuses da Ática, nem com Shakespeare. Entretanto, inspira à civilização ocidental um modelo de romance familiar que prevalecerá durante um século.

O modelo de romance familiar ao qual a autora se refere não é outro senão a família edipiana, que equivalia à família burguesa. $\mathrm{O}$ complexo de Édipo seria então, segundo Roudinesco (2003) e também segundo Lacan (1987), a maneira que Freud encontrou de restituir ao pai um destaque na família. Assim, o complexo de Édipo, segundo a letra desses autores, pos- 
sibilitou à instituição familiar sobreviver a um colapso generalizado que a ameaçava destacando uma função simbólica que girava em torno da figura do pai. O pai em destaque no complexo de Édipo representa, de certa maneira, a sobrevivência da autoridade do pai que se encontrava ameaçada, sob uma outra forma de atuação - designada por Freud de complexo paterno e por Lacan de função paterna.

Todos os trabalhos recentes sobre a história das origens da psicanálise, [...], mostram que a psicanálise nasce da interrogação que atravessa a sociedade vienense do fim do século passado face ao declínio da família patriarcal [...]. Existia em Freud uma vontade de revalorizar simbolicamente o pai [...]. É ainda Jacques Lacan quem, sob a forma de uma função simbólica essencial à organização da família, reintroduz a imagem do pai $^{2}$ (ROUDINESCO apud ZAFIROPOULOS, 200I, p. I2)

Vamos direto à letra de Freud. Se recorrermos às cartas de Freud a Fliess, na Carta 64, publicada em I897, percebemos a manifestação do desejo de encontrar um pai causador da neurose, desejo interpretado a partir de um sonho seu. Num anexo a essa carta, o Rascunho N, Freud persiste nessa ideia, porém não mais como um desejo pessoal que aparece em sonho, mas sim como uma ideia de um pai e uma mãe participantes da neurose do filho, ideia essa que começa a ganhar corpo na sua obra. Ele continua: "Os impulsos hostis contra os pais (desejo de que eles morram) também são um elemento integrante das neuroses. [...] Parece que esse desejo de morte, no filho, está voltado contra o pai e, na filha, contra a mãe" (FREUD, 1996, p. 304). Essa parece ser a primeira vez que se manifestam indícios do complexo de Édipo que Freud desenvolverá meses depois. $\mathrm{Na}$ Carta 7I, também publicada em I897, mais ou menos cinco meses depois, Freud vai se aproximando cada vez mais do conceito de complexo de Édipo, mencionando pela primeira vez o nome de Édipo: "Verifiquei, também no meu caso, a paixão pela mãe e o ciúme do pai, e agora considero

2 Original em Francês. 
isso como um evento universal do início da infância...”. Continua: “Cada pessoa da platéia foi, um dia, em germe ou na fantasia, exatamente um Édipo como esse, e cada qual recua, horrorizada, diante da realização de sonho aqui transposta para a realidade...”. (FREUD, i996, p. 316)

É em I900, pouco tempo depois da Carta 7I, com $A$ Interpretação de sonbos que encontraremos publicada pela primeira vez a referência ao Édipo. Nesse momento sua preocupação central parece ser a relação pai e filho, desenvolvendo a partir daí todo um pensamento de reflexão a respeito do Édipo Rei de Sófocles: o filho que mata o pai e se casa com a mãe, sem o saber, e que sente culpa ao descobrir-se impuro, punindo-se com a cegueira.

Freud (2003, p. 65) propõe com o complexo de Édipo uma outra ordem familiar, a edipiana, que, segundo Roudinesco, "restabelece simbolicamente diferenças necessárias à manutenção de um modelo de família que se temia que estivesse desaparecendo na realidade”. Se essa foi a pretensão de Freud, não foi isso que o desenrolar dos acontecimentos históricos nos demonstraram, como atesta a própria Roudinesco. Antes de alcançar seu propósito de restaurar a antiga ordem familiar, a psicanálise "contribuiu para a eclosão, no seio da família afetiva, de novos modos de parentalidade [...] ao mesmo tempo se tornando o fermento de um duplo movimento social que vinculava a emancipação das mulheres e dos filhos [...] à rebelião dos filhos contra os pais”. (FREUD, 2003, p. 93)

Porém, como denuncia a sequência dos acontecimentos, esse duplo movimento social não podia ainda acontecer senão de modo silencioso, "autorizados em surdina” (FOUCAULT, I988, p. Io), o que nos faz retornar à Introdução de Foucault.

No regime vitoriano, essa rebelião só podia se manifestar num outro lugar - no íntimo de cada sujeito, e a histeria era o produto dessa repressão. É para onde nos guia a leitura de Roudinesco (20I4, p. 63, tradução nossa): 


\begin{abstract}
A histeria se tornou em toda a Europa a expressão de uma revolta impotente das mulheres contra o poder patriarcal preocupado com um espectro de uma possível feminização do corpo social. À Viena, essa revolta restava confinada no círculo das famílias burguesas. Mas em Paris - vila dos movimentos revolucionários - ela adquiria um sentido mais político que a Medicina do Estado se pretendia ao ser popular e republicana.
\end{abstract}

Dessa forma, a nova ordem econômica se enraíza poderosamente na intimidade mais recôndita do sujeito humano. $\mathrm{O}$ que a burguesia inaugura vai muito além de uma nova ordem social, econômica e cultural. Ela instaura uma nova maneira de compreender o homem e sua subjetividade. E nessa perspectiva é Roudinesco (20I4) que nos direciona à compreensão da psicanálise - a partir dos estudos sobre a histeria - como um movimento político, econômico e cultural, no sentido mesmo de resguardar a sociedade moderna das ameaças que as mudanças decorrentes das revoluções fins de século XVIII acabaram por influenciar:

O paradigma da 'mulher histérica' [...] dá lugar a um estado de sociedade onde as mulheres não tinham outro meio, de exprimir sua aspiração à liberdade, a não ser pela exibição de um corpo em sofrimento. [...] As burguesas ganham o direito à uma vida privada, a um sentimento íntimo. Seu sofrimento existencial permite aos homens da ciência elaborar uma nova teoria da subjetividade. (ROUDINES$\mathrm{CO}, 2014$, p. 87)

O que Foucault irá demonstrar, no curso do seu texto, é que o triunfo do discurso das ciências humanas, e aqui mais estritamente o discurso da psicanálise, vincula-se estreitamente às formas de poder na tecelagem das condutas. É essa ordenação, categorização das condutas que acaba por se constituir uma nova forma de organização psíquica própria das sociedades modernas. Submetida não mais à autoridade do patriarca, mas aos novos modos de parentalidade que funcionam a partir de seus efeitos simbólicos. 
As histéricas são, portanto, produtos de uma sociedade que quer escamotear as verdades das famílias burguesas. Freud é ele mesmo efeito dessas variações que sua época promove nas famílias, assim como sua obra também o é. Nesse adentro da psicanálise como discurso de um saber, usando a lupa de Foucault, numa historicização das ciências do homem, percebemos o quanto a obra freudiana equivale ao testemunho dos desencontros e desacertos da família burguesa. O salto, no entanto, vale destacar, é perceber-se não como um Édipo, culpado e cego, ou um Hamlet, culpado e neurótico, mas sim compreender que, na realidade, algo de si mesmo sempre escapa ao homem.

[...] Freud tinha a conviç̧ão que sua doutrina devia ser antes uma ciência
do psiquismo, susceptível de subverter o campo da psicologia, e onde
os fundamentos se inscreveriam na biologia e nas ciências naturais. Em
realidade, ele traz com sua obra é bem outra coisa: Uma revolução do
íntimo, resultado do Iluminismo sombrio e do Romantismo Noir, uma
revolução ao mesmo tempo racional e assombrada pela conquista de
rios subterrâneos [...] tal era a promessa da viagem freudiana ao coração
de um inconsciente definido como 'outra cena', e que supunha uma or-
ganização das estruturas da parentalidade suscetível de perceber as mo-
dalidades de uma nova ordem familiar do qual ele desejava ser o clínico,
mas também era o ator. (ROUDINESCO, 20I4, p. Io4)

Até aqui, o que obtivemos? Primeiro, um deslocamento de olhar: não nos deve interessar exclusivamente o conteúdo quando estudamos o sujeito humano, especialmente a família, como estrutura aglutinadora. Foucault se diverte com as ilusões metodológicas que se propõem extrema objetividade sem uma olhadela crítica para o modo mediante o qual o discurso é composto. Portanto, o primeiro ganho é de ordem metodológica. Quer dizer, o esforço do autor não se encaminhará para um exercício do tipo epistemológico, demonstrando a logicidade conceitual dos discursos constitutivos das ciências humanas. Sua preocupação, ao contrário, é rastrear as condições pelas quais tal ou qual discurso foi construído. Assim tentamos fazer com a contribuição da obra de Roudinesco. 
Em segundo lugar, a certeza de que pouco sabemos. Isso, o velho e bom Descartes já nos ensinou há quase quatro séculos com a sua moral provisória. Cabe aos cientistas que enunciam verdades terem em mente que a parte significativa dos seus discursos é tão somente da ordem da doxa, porque a realidade, e aqui a realidade familiar, é muito mais complexa. Pouco sabemos, portanto, sobre a família e sobre a sexualidade, pois que as construções sobre esses conceitos são mediados pelos discursos dos saberes. Pouco sabemos igualmente sobre nós mesmo, sobre nossos desejos, a liberdade subjetiva só é possível ao preço da aceitação de um determinismo inconsciente. (ROUDINESCO, 20I4) É impossível, portanto alcançarmos toda verdade do sujeito, algo resta sempre inconsciente.

Para concluir, todo o encaminhamento que Foucault oferece à sua investigação delineada nessa Introdução de sua obra última revela que o resultado ao qual seguramente chegamos confirma que o uso da categoria família não é feito como e enquanto categoria epistêmica. Trata-se bem mais de refletir acerca dos discursos que erigem categorias, sopesando os resultados invisíveis deles. Neste caso particular, bem mais que identificar a força coercitiva da família na constituição do sujeito, o que seguramente Foucault ressalta é que ela seja um locus que encerra também uma força promotora de condutas. Como lugar de poder, não pode ser concebido como exclusivamente restritivo, repressor. Para além disso, ali o sujeito torna-se o que é, inscrevendo nela seus próprios movimentos modeladores. Como o sexo, a família é uma força incitadora de subjetivação. Em que consiste isso? Certamente temos aqui um outro tema para desdobramentos futuros. 


\section{Referências}

FONSECA, M. Michel Foucault e a constituição do sujeito. São Paulo: Educ, 1995.

FOUCAULT, M. História da sexualidade: a vontade de saber. São Paulo: Graal, I985. v. I.

FREUD. Carta 52 (I896). In: FREUD. Extratos dos documentos dirigidos a Fliess (1950 [1892-1899]). Rio de Janeiro: Imago, 1996. p. 28I-288. (Edição standard brasileira das obras psicológicas completas de Sigmund Freud, v. I).

FREUD. Carta 64 (I897a). In: FREUD. Extratos dos documentos dirigidos a Fliess (1950 [1892-1899]). Rio de Janeiro: Imago, 1996. p. 303-304. (Edição standard brasileira das obras psicológicas completas de Sigmund Freud, v. I).

FREUD. Carta 7I (1897b). In: FREUD. Extratos dos documentos dirigidos a Fliess (1950 [1892-1899]). Rio de Janeiro: Imago, 1996. p. 314-317. (Edição standard brasileira das obras psicológicas completas de Sigmund Freud, v. I).

FREUD. A interpretação dos sonbos (I900). Rio de Janeiro: Imago, 1996. (Edição standard brasileira das obras psicológicas completas de Sigmund Freud, v. I).

GIARD, L. Michel Foucault, lire l'oeuvre. Paris: J. Millon, 1992.

HAN, B. L 'Ontologie Manquée de Michel Foucault Paris: J. Millon Collection Krisis, 1998.

HURSTELS, F. As novas fronteiras da paternidade. São Paulo: Papirus, I999. p. 23I.

JALÓN, M. El Laboratório de Foucault, Decifrary Ordenar Buenos Aires: Antrophos, 1994 .

LACAN, J. A familia. Lisboa: Assírio \& Alvim, 1987.

ROUDINESCO, E. A familia em desordem. Rio de Janeiro: Jorge Zahar, 2003. ROUDINESCO, E. Sigmund Freud en son temps et dans le nôtre. Paris: Éditions du Seuil, 2014.

TRONCA, I. Foucault Vivo. Campinas: Pontes, 1987.

VERÓN, E. Analisis de Michel Foucault. Buenos Aires: Tiempo Conteporáneo, I996. 
VEYNE, P. Como se escreve a bistória. Foucault revoluciona a história. Brasilia: $\mathrm{UNB}, 1982$.

ZAFIROPOULOS, M. Lacan et les sciences sociales. Le déclin du père (1938I953). Paris: PUF, 200I. p. 258.

80

क्के 